\title{
Comparative study of clinical outcomes following conventional versus laser assisted tonsillectomy
}

\author{
Vijayasundaram S. ${ }^{1}$, Satyaprabhakara Rao Y. ${ }^{2}$, Raja Preetham B. ${ }^{3}$ \\ ${ }^{1}$ Dr. Vijayasundaram Sundararajan, Associate Professor, ${ }^{2}$ Dr. Satyaprabhakara Rao, Professor and Head of the \\ Department, ${ }^{3}$ Dr. Raja Preetham B., Junior Resident; all authors are affiliated with Department of Otorhinolaryngology \\ Head and Neck Surgery, NRI Medical College, Guntur, Andhra Pradesh, India.
}

Corresponding Author: Dr. Vijayasundaram S., Associate Professor, Department of Otorhinolaryngology Head and Neck Surgery, NRI Medical College, Guntur, Andhra Pradesh, India. E-mail: dr.vijayasundaram@gmail.com

\begin{abstract}
Introduction: A number of published studies have compared the KTP laser with standard dissection technique for tonsillectomy and safety of the laser is well described. This study aims to have a comprehensive insight into the comparative clinical outcomes for conventional tonsillectomy with KTP-532 laser assisted tonsillectomy. Materials and Methods: Prospective, comparative study enrolling 60 patients with chronic adenotonsillitis who visited the department of ENT, NRI Medical college and General hospital of a Tertiary referral centre from June 2018 to July 2019. After confirming the diagnosis, the patients were subjected to a detailed history and clinical examination and the patients were divided into two groups - The patients (30 cases) in the first half of this period underwent conventional tonsillectomy whereas the rest (30 cases) underwent laser tonsillectomy. All patients in this study were assessed for operative time, blood loss, post-operative pain, tonsillar fossa healing and incidence of haemorrhage. The differences between studied groups less than $0.5(\mathrm{p}<0.05)$ considered significant statically. Results: It was observed that total time taken for surgery, mean blood loss, intra-op blood loss, and post-op pain at Day 0 were comparatively less in Group B. While post-op pain at Day 14 was less in Group A. Moreover, Post -op Pain at Day 7, incidence of haemorrhage and healing of tonsillar fossa showed no significant difference in both groups. Conclusion: Laser assisted tonsillectomy is a safe alternative to conventional tonsillectomy associated with low intraoperative bleeding and less time-consuming surgery when compared to conventional tonsillectomy.
\end{abstract}

Keywords: Tonsillectomy, KTP-532, Laser assisted, Conventional tonsillectomy, Haemorrhage

\section{Introduction}

The first Tonsillectomy was reported by a Roman physician Celsus about 2000 years ago [1]. Celsus described his surgical procedure as scratching around the tonsils, releasing, and then removing them. He used vinegar and milk for hemostasis to reduce haemorrhage. Tonsillectomy is one of the most common paediatric otolaryngologic surgical operations done all over the world [2].

The most common indications of tonsillectomy are sleep-disordered breathing, tonsillitis, and peritonsillar abscess. The most widely used technique to perform this operation is cold dissection method in which scalpel or surgical knife is utilized. After tonsillectomy, children should tolerate sore throats for one to two

Manuscript received: $8^{\text {th }}$ August 2019

Reviewed: $18^{\text {th }}$ August 2019

Author Corrected: $24^{\text {th }}$ August 2019

Accepted for Publication: $29^{\text {th }}$ August 2019 weeks and mostly experience referred pain in the ear. Advancements in technology have affected the surgical methods of tonsillectomy for reaching the desired benefits. This helps in reducing operative time, intraoperative blood loss, post-operative pain, and prolonged morbidity. The basic principle for performing tonsillectomy, dissection of all tonsillar tissue free of the underlying pharyngeal constrictor muscle, has not changed significantly in more than 60 years.

Many methods have been developed over the years to ablate tonsillar tissue such as the use of lasers, radiofrequency, coblation, bipolar, etc. Potassiumtitanyl-phosphate (KTP-532) is an easily manipulated type of laser that could be delivered by an endostat fiber. Several published studies have compared the KTP laser with standard dissection technique for tonsillectomy. Some concluded that the usefulness of 
the KTP laser in tonsillectomy remains questionable [3], whereas Kaluskar suggested that the KTP laser is an ideal tool for tonsillectomy [4]. This study aims to have a comprehensive insight into the comparative clinical outcomes for conventional tonsillectomy with KTP-532 laser assisted tonsillectomy.

\section{Materials And Methods}

Study design: Prospective, comparative study.

Setting: ENT Department of a tertiary care hospital (NRI Medical College and General Hospital, Chinakakani).

Study period: June 2018-June 2019.

Sample size: 60 patients ( 30 in each category).

\section{Inclusion Criteria}

\section{Chronic Adenotonsillitis}

- Seven episodes of tonsillitis in the preceding year or

- Five episodes in each of the preceding two years or

- Three episodes in each of the preceding three years

2. Age group between 4 years to 18 years

\section{Exclusion Criteria}

1. Acute infection

2. Tumours of tonsils

3. Bleeding or clotting disorders

4. Tonsillectomy is done as an approach for an elongated styloid process

5. Age group less than 4 years or more than 18 years

6. Comorbid conditions (hypertension, cardiac disease, diabetes mellitus, bronchial asthma)

Study Group: Patients were divided into Group A and Group B. This was performed using a blocked randomization scheme. Computer-generated random numbers were used to divide patients into the two groups.

- Group A- patients underwent conventional tonsillectomy (30 patients)

- Group B- patients underwent laser-assisted tonsillectomy (30 patients)

Total number of patients -60

Methodology: The patients selected as per the inclusion criteria formulated were enrolled in the study after obtaining consent. They were evaluated as follows:

- Patients who were selected were subjected to a detailed history and clinical examination.

- All subjects including their parents were counselled about the nature of the study, and the informed consent was taken.
- Blood investigations like haemoglobin percentage, total count, differential count, bleeding time, clotting time, prothrombin time, partial thromboplastin time, international normalized ratio, blood grouping \& typing, and urine routine were performed.

- Surgical time was measured from the time of insertion of Boyle-Davis mouth gag to the removal of mouth gag for tonsillectomy.

- Intraoperative blood loss was measured by weighing the swabs before and after tonsillectomy and by measuring the amount in the suction bottle.

- The blood loss in millilitres in the suction was calculated as the difference between this amount and the irrigation fluid used

- Post-operative pain scores were charted on day 0, day 7 and day 14 using: Wong-Baker Faces pain scale for 4-12 years. A numerical rating scale for 1318 years, scale in which 0 indicates no pain and 10 indicates very severe pain.

- The patients were discharged and called for followup at the end of $1^{\text {st }}$ week, $2^{\text {nd }}$ week and $4^{\text {th }}$ week from date of surgery to assess the tonsillar fossa.

- Tonsillar fossa was assessed by calculating the rate of healing, as determined by the size of the posttonsillectomy slough. The size of the posttonsillectomy slough was taken as an indication of the rate of the healing process. Five grades of healing are considered: $0,25,50,75$ and 100 percent, according to the size of the slough in comparison with the areal size of the original postoperative bed [5], where

- 0 percent represented a bed completely covered with slough

- 25 percent represented Slough covers $75 \%$ of tonsillar bed

- 50 percent represented Slough covers $50 \%$ of tonsillar bed

- 75 percent represented Slough covers 25\% of tonsillar bed

- 100 percent represented a completely healed bed with no slough.

The lower grade was selected in case of inequality between both sides.

- All patients were monitored closely in the postoperative period to check for any eventuality of bleeding with respect to the laterality, quantum of bleed and their subsequent management.

- The data obtained from both groups were compared and statistically analysed. 


\section{Original Research Article}

Statistical Analysis: Mean and standard deviation were estimated from the sample for each study group. Student ' $t$ ' test and chi-square test was applied to find the level of significance between Group A and Group B. In the study, $\mathrm{p}<0.05$ was considered as the level of significance.

\section{Results}

A total of 60 patients included in this study, with 30 patients in each group. They were divided into two groups as Group A and Group B. Patients in Group A underwent conventional tonsillectomy, and patients in Group B underwent laserassisted tonsillectomy. All patients were assessed for operative time, blood loss, post-operative pain, tonsillar fossa healing and incidence of haemorrhage. The data collected were tabulated and statistically analyzed in consultation with a qualified statistician.

Age distribution: There were a total of 60 patients included in this study with 30 patients in each group. The mean age in Group A was 10.4 \pm 3.6 years, and that in Group B was 8.3 \pm 2.9 years. Figure 1 shows the number of patients in each age group.

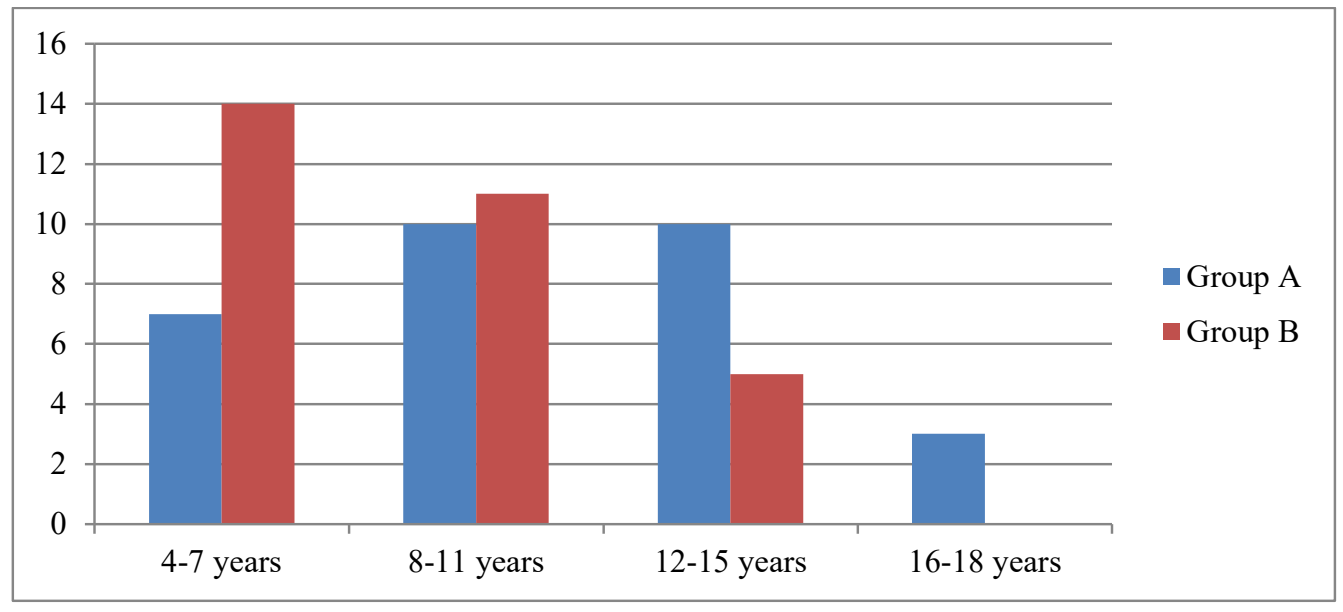

Figure-1: Age distribution

Sex distribution: There were 12 males and 18 females in Group A and 18 males and 12 females in Group B

Time Taken for Surgery: Surgical time was measured from the time of insertion of Boyle-Davis mouth gag to the removal of mouth gag for tonsillectomy (Table 1).

Table 1: Time taken for surgery in both groups

\begin{tabular}{|c|c|c|}
\hline Surgery Time & Group A & Group B \\
\hline$<\mathbf{1 5}$ min & $0(0 \%)$ & $21(70 \%)$ \\
\hline $\mathbf{1 5}-\mathbf{3 0}$ min & $2(6.7 \%)$ & $9(30 \%)$ \\
\hline$>\mathbf{3 0}$ min & $28(93.3 \%)$ & $0(0 \%)$ \\
\hline
\end{tabular}

$P$ value $=0.0001$

The mean time taken in Group A patients was $36.60 \mathrm{~min} \pm 5.17 \mathrm{~min}$. In Group B patients, the mean time taken was 13.54 $\min \pm 3.03 \mathrm{~min}$. Hence, the total time taken for surgery is significantly less in Group B when compared to Group A, and it is statistically significant.

Intra-operative Blood Loss: Intraoperative blood loss was measured by weighing the swabs before and after tonsillectomy and by measuring the amount in the suction bottle. The blood loss in millilitres in the suction was calculated as the difference between this amount and the irrigation fluid used. (Table 2) 
Table-2: Intra Op blood loss of patients in both groups.

\begin{tabular}{|c|c|c|}
\hline Blood Loss & Group A & Group B \\
\hline$<\mathbf{2 0} \mathbf{~ m l}$ & $0(0 \%)$ & $27(90 \%)$ \\
\hline $\mathbf{2 0}-\mathbf{4 0} \mathbf{~ m l}$ & $14(46.7 \%)$ & $3(10.0 \%)$ \\
\hline$>\mathbf{4 0} \mathbf{~ m l}$ & $16(53.3 \%)$ & $0(0 \%)$ \\
\hline
\end{tabular}

$P$ value $=0.0001$

The mean blood loss in Group A patients is $42.63 \mathrm{ml} \pm 12.71 \mathrm{ml}$. In Group B patients, the mean blood loss is $14.43 \mathrm{ml} \pm$ $7.78 \mathrm{ml}$.

Hence, the total intraoperative blood loss in Group B is less compared to Group A and it is statistically significant.

Post Op pain score: Post-operative pain scores were charted on day 0, day 7 and day 14 using Wong-Baker Faces pain scale for 4-12 years and numerical rating scale for 13-18 years scale in which 0 indicates no pain and 10 indicates very severe pain (Table 3 ).

Table-3: Post op pain score in Day 0, day 7 and day 14.

\begin{tabular}{|c|c|c|c|c|c|c|}
\hline \multirow{2}{*}{ Pain Score } & \multicolumn{2}{|c|}{ Day 0 } & \multicolumn{2}{c|}{ Day 7 } & Day 14 \\
\hline & A & B & A & B & A & B \\
\hline$<3$ & $0(0 \%)$ & $19(63.3 \%)$ & $24(80 \%)$ & $25(83.3 \%)$ & $30(100 \%)$ & $15(50 \%)$ \\
\hline $4-6$ & $16(53.3 \%)$ & $11(36.7 \%)$ & $6(30.0 \%)$ & $5(16.7 \%)$ & $0(0 \%)$ & $15(50 \%)$ \\
\hline $7-10$ & $14(46.7 \%)$ & $0(0 \%)$ & $0(0 \%)$ & $0(0 \%)$ & $0(0 \%)$ & $0(0 \%)$ \\
\hline & \multicolumn{2}{|r|}{$\mathrm{p}=0.0001$} & $\mathrm{p}>0.05$ & $\mathrm{p}=0.0001$ \\
\hline
\end{tabular}

At Day 0, none of the Group B patients had pain scores more than 7. Group B had comparatively less pain and it is statistically significant. No significant difference in pain scores was noted on day 7 between the two groups.

At Day 14, all patients of Group A had very little pain whereas patients in Group B who previously had less pain reported to have worsening of pain. Group B had comparatively more pain and it is statistically significant.

Incidence of haemorrhage: No significant difference in the incidence of haemorrhage between the two groups was noted (Table 4).

Table-4: Incidence of haemorrhage

\begin{tabular}{|c|c|c|c|}
\hline \multirow{2}{*}{ Haemorrhage } & \multicolumn{2}{|c|}{ Group } & \multirow{2}{*}{ P Value } \\
\cline { 2 - 4 } & A & $0(0 \%)$ & 0.313 \\
\hline Reactionary & $1(3.3 \%)$ & $3(10.0 \%)$ & 0.64 \\
\hline Secondary & $2(6.7 \%)$ & B & \\
\hline
\end{tabular}

Healing of tonsillar fossa: Tonsillar fossa was assessed by calculating the rate of healing, as determined by the size of the post-tonsillectomy slough at the end of $1^{\text {st }}, 2^{\text {nd }}$ and $4^{\text {th }}$ week. 
Table-5: Healing of tonsillar fossa.

\begin{tabular}{|c|c|c|c|c|c|}
\hline & Group & Mean (\%) & Std. Deviation & $\begin{array}{l}\text { Std Error } \\
\text { Mean }\end{array}$ & P Value \\
\hline \multirow{2}{*}{$1^{\text {st }}$ week } & $\mathbf{A}$ & 41.67 & 11.987 & 2.188 & \multirow{2}{*}{0.071} \\
\hline & B & 35.83 & 12.600 & 2.300 & \\
\hline \multirow{2}{*}{$2^{\text {nd }}$ week } & $\mathbf{A}$ & 68.33 & 11.244 & 2.053 & \multirow{2}{*}{0.065} \\
\hline & B & 62.50 & 12.717 & 2.321 & \\
\hline \multirow{2}{*}{$4^{\text {th }}$ week } & $\mathbf{A}$ & 95.83 & 9.476 & 1.730 & \multirow{2}{*}{0.082} \\
\hline & B & 90.83 & 12.253 & 2.237 & \\
\hline
\end{tabular}

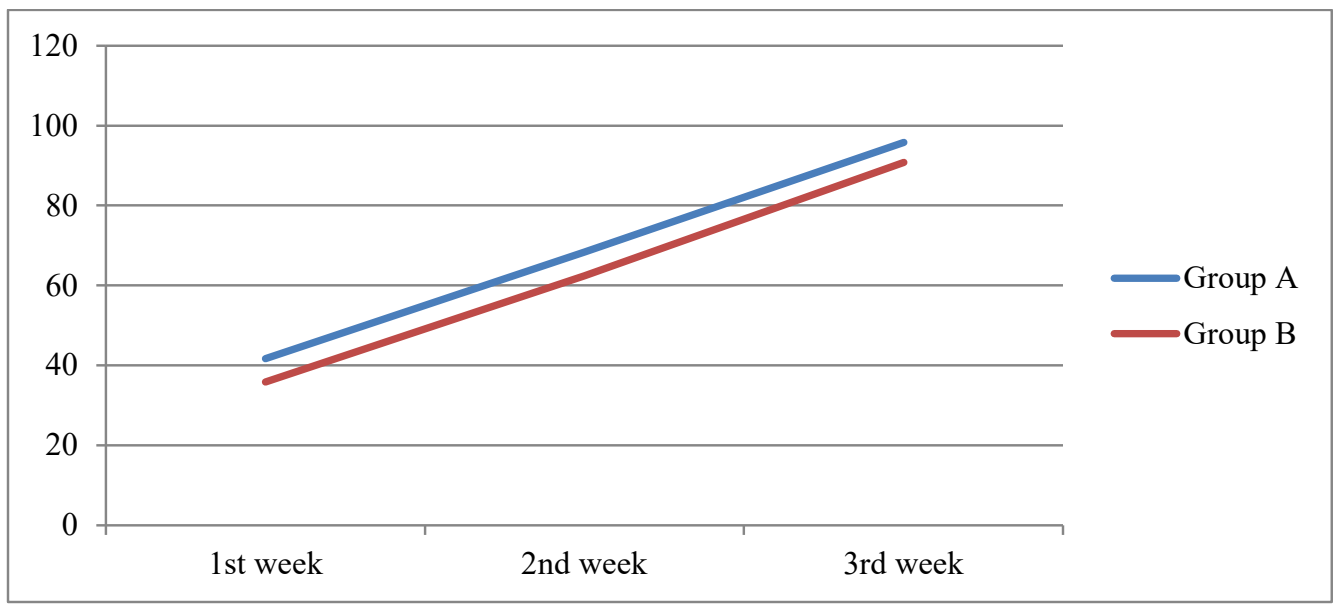

Figure-2: Healing of tonsillar fossa

Group A showed slight faster healing of tonsillar fossa on comparing with Group B but it is statistically not significant. (Figure 2). Hence there is no significant difference in the tonsillar fossa healing rate between Group A and Group B.

\section{Discussion}

Tonsillectomy as a surgical technique has evolved over the years. It is still the most frequent surgery performed in children by Otolaryngologist [2]. Many types of instrumentation and different techniques have been attempted and published over two centuries [3]. Lasers have been used in otolaryngology for many years. The $\mathrm{CO}_{2}$ laser has been a popular tool for tonsillectomy and adenoidectomy and is claimed to be useful [6].

However, the instrumentation is cumbersome and therefore not used these days routinely. In contrast, the KTP laser is easy to manipulate as the laser is delivered via an endostat fiber. Several published studies have compared the KTP laser with standard dissection technique for tonsillectomy. Laser surgery appeared to lead to slow wound healing during the whole postoperative course with significant difference compared with the conventional method. Disadvantages of postoperative pain and the possibility of secondary infection due to slow wound healing could be prevented by application of antibiotics and an anodyne. The most frequent non-pharmacological strategies used to manage pain include distraction (cognitive behavioural method) and having cold liquids/foods (ice cream) by mouth. In the present study, 60 patients were included, with 30 patients in each group.

They were divided into two groups by block randomization, and the main parameters evaluated were operative time, intra-operative blood loss, postoperative pain and other postoperative complications, which was compared with each of the techniques employed for tonsillectomy. On analysing the data shown in the master chart, the average time taken to perform conventional tonsillectomy was $36 \mathrm{~min} 45 \mathrm{sec}$ with a standard deviation of $5 \mathrm{~min} 10 \mathrm{sec}$. However, it varied between $20 \mathrm{~min} 10 \mathrm{sec}$ to $45 \mathrm{~min}$. In laser-assisted tonsillectomy, the time it was taken varied from $8 \mathrm{~min}$ 


\section{Original Research Article}

to $20 \mathrm{~min}$ with an average of $13 \mathrm{~min} 30 \mathrm{sec}$ with a standard deviation $3 \mathrm{~min}$. This reduction in the intraoperative time indirectly reduces anaesthetic time.

In the present study, operative time was significantly shorter in the laser group. This finding is in accordance with a similar study by Mohammadi et al., according to which, in laser tonsillectomy, there was a significant reduction in operation time ( 5 vs 11.3 minutes $\mathrm{p}<0.05$ ) [7].

In the present study, the average blood loss in case of conventional tonsillectomy is $42.63 \mathrm{ml}$ with a standard deviation of $12.71 \mathrm{ml}$ when compared to $14.43 \mathrm{ml}$ with a standard deviation $7.78 \mathrm{ml}$ in case of laser-assisted tonsillectomy. None of the patients had intraoperative blood loss less than $20 \mathrm{ml}$ in conventional tonsillectomy compared to 27 patients in laser-assisted tonsillectomy.

This finding was in accordance with a similar study by Mohammadi et al., where it was found that there was a significant reduction in intraoperative blood loss (5 vs $15 \mathrm{ml} \mathrm{P}<0.005$ ) with laser tonsillectomy compared to conventional tonsillectomy [7].Following tonsillectomy, immediate hospital readmission is mandatory in case of secondary bleeding, and an intensive care unit should intensively take care of the patient and potentially, radiological embolization of the vascular bleeding network might be a lifesaving choice.

In the present study, the postoperative pain scores were charted on day 0 , day 7 and day 14 showed less pain in the immediate post-op period (Day 0) and worsening of pain 2 weeks later (Day 14) which are statistically significant. These results are in contrast to a Malaysian study by Ishlah et al., where the total postoperative pain was not significantly different between the two groups [8]. Many works of literature including Tugrul et al., mentioned that postoperative pain should be minimized not only for the patients' comfort but also the pain usually impair swallowing with a significant risk of dehydration, infection and secondary haemorrhage [9]. The incidence of reactionary haemorrhage was 3.3\% in the conventional group compared to $0 \%$ in the laser group. This could be attributed to cutting and simultaneous haemostasis by sealing the blood vessel lumen by virtue of tissue heating in Laser assisted tonsillectomy technique [10-12].

In the present study, the incidence of secondary haemorrhage was $6.7 \%$ in the conventional group compared to $10.0 \%$ in the laser group. In the present study, there is no significant difference in the tonsillar fossa healing rate between the two groups.
Limitations: Of the KTP/532 tonsillectomy includes increased cost and laser malfunctions.

\section{Conclusion}

- Laser-assisted tonsillectomy has shown to have significantly shortened the operative time.

- Intraoperative blood loss was found to be minimal in case of laser-assisted tonsillectomy.

- Immediate postoperative pain was less with laserassisted tonsillectomy when compared to conventional tonsillectomy

- During the period of convalescences, two weeks post-operatively, the laser group had comparatively more pain.

- Patients in the conventional group had better functional outcomes at the end of $4^{\text {th }}$-week postoperatively.

- The rate of tonsillar fossa healing and the incidence of reactionary or secondary haemorrhage were not significantly different between the two groups.

- Laser-assisted tonsillectomy is a safe alternative to conventional tonsillectomy, the attributes of cost impacts notwithstanding.

\section{What this study adds to the existing knowledge?}

The study statistics confirmed the various parameters like operative time and intraoperative blood loss of KTP laser assisted tonsillectomy, which helps to minimise the ambiguity regarding the use of lasers in tonsillectomy.

\section{Author's contribution}

Dr. S. Vijaya Sundaram: Surgical technique incorporation, Data collection, manuscript preparation.

Dr. Y. Satya Prabhakara Rao: Surgical technique incorporation, Data collection, manuscript correction.

Dr. Raja Preetham B: Assisted surgeries, Data collection, Review of literature, statistical analysis, manuscript preparation.

Funding: Nil, Conflict of interest: Nil Permission from IRB: Yes

Acknowledgments: Authors would like to acknowledge laser technician, O.R supporting staff statistician for their inputs and support throughout the study. 


\section{References}

1. Curtin JM. The history of tonsil and adenoid surgery. Otolaryngol Clin North Am. 1987;20(2):415-419.

2.Timms MS, Temple RH. Coblation tonsillectomy: a double blind randomized controlled study. J Laryngol Otol. 2002;116(6):450-452.doi:10.1258/00222150 2191 1031

3. Auf I, Osborne JE, Sparkes C, Khalil H. Is the KTP laser effective in tonsillectomy? Clin Otolaryngol Allied Sci. 1997;22(2):145-146. doi: https://doi.org/10.1046/j. 1365-2273.1997.d01-305.x

4. Kaluskar SK. KTP-532 laser tonsillectomy--a potential day-case procedure? J Laryngol Otol. 1996; 110(2):205-207. doi:10.1017/s0022215100133183

5. Elwany S, Nour YA, Magdy EA. Does laryngopharyngeal reflux affect healing and recovery after tonsillectomy? J Laryngol Otol. 2008;122(6):603-608. Epub 2007 Jul 11. doi:10.1017/S0022215107009760

6. Martinez SA, Akin DP. Laser tonsillectomy and adenoidectomy. Otolaryngol Clin North Am. 1987;20 (2):371-376.

7. Mohammadi G, Moghaddam YJ, Radfar R. CO2 laser tonsillectomy: A comparison with conventional technique. Rawal Med J. 2007;32(2):187-189.
8. Ishlah LW, Fahmi AM, Srinovianti N. Laser versus dissection technique of tonsillectomy. Med J Malaysia. 2005;60(1):76-80.

9.TugrulS, Degirmenci N, Eren SB, Dogan R, Veyseller $\mathrm{B}$, Ozturan O. Analgesic effect of magnesium in posttonsillectomy patients:a prospective randomised clinical trial. European Arch Oto-Rhino-Laryngology. 2015; 272 (9): 2483-2487. doi: 10.1007/ s00405-014- 32 $19-8$

10. Windfuhr JP, Schloendorff G, Baburi D, Kremer B. Lethal outcome of post-tonsillectomy hemorrhage. Arch Otorhinolaryngol. 2008;265(12):1527-1534 doi: 10.1007/s00405-008-0699-4

11. Saito T, Honda N, Saito H. Advantage and disadvantage of KTP-532 laser tonsillectomy compared with conventional method. Aur Nas Lary. 1999;26 (4):447-452. doi: 10. 1016/ S0385-8146 (99) 000 $25-5$

12. Strunk CL, Nichols ML. A comparison of the KTP/ 532-laser tonsillectomy vs. traditional dissection/ snare tonsillectomy. Otolaryngol Head Neck Surg. 1990; 103 (6): 966-971. doi:10.1177/ 019459989010300 614

\section{How to cite this article?}

Vijayasundaram S, Satyaprabhakara Rao Y, Raja Preetham B. Comparative study of clinical outcomes following conventional versus laser assisted tonsillectomy.Trop J Ophthalmol Otolaryngol.2019;4(4):296302.doi:10.17511/jooo.2019.i04.07 